\title{
Research on the Orbital Debris Removing Business
}

\author{
Xiaohua Yang \\ Department of Electrical Engineering and Automation, North China Electric Power University, \\ Baoding, 071000, China \\ Email: 15932138793@163.com
}

Keywords: Orbital debris removing business, Principal components analysis, Profit Evaluate Model

\begin{abstract}
The increasing number of space debris is an ongoing problem which has caused a considerable harm to all kinds of spacecraft. The main target of this paper is to make an optimal business plan that private firms could adopt in the field of active debris removal (ADR). Thus, ADR is just simplified as a business practice. We discuss four ADR projects, including Laser Orbital Debris Removal, Cube Sail, Clean Space One, and Space Debris Micro Remover. The Profit Evaluate Model analyzes the overall profit and yearly profit under the criteria of various operating period; the Principal Component Analysis Model focuses on the evaluation of optional main factors. By applying those simulated parameters, we reach a conclusion that the best single project to remove space debris is Cube Sail.
\end{abstract}

\section{Introduction}

The increasing number of space debris was first pointed by Kessler and Cour Palais [1], and then gathers the worldwide attention due to the gradual deterioration. At present, the most of debris dispread at altitudes below $2000 \mathrm{~km}$ with large concentrations at several altitudes particularly in lower earth orbit (LEO) [2]. Many scientists have warned that, if we take no action in the future, the debris number will keep growing in LEOs even there is no new launch of aircrafts.

Table 1.The number of space debris varied in mass

\begin{tabular}{cccc}
\hline Size & $>10 \mathrm{~cm}$ & $>1 \mathrm{~cm}$ & $>1 \mathrm{~mm}$ \\
\hline Number & 29,000 & 670,000 & $>170,000,000$ \\
\hline
\end{tabular}

Resource: http://www.esa.int/

At present, there are many ADR technologies, for example Small Debris Collection, Laser Orbital Debris Removal, Trash Tenders and Attachable Devices, Dual-Use Orbit Transfer Vehicles, Space-Based Lasers, Space Tethers [3]. Although concepts for the ADR project have been proposed for decades, not until recently has the government begun to take any business activity to operate them. As no one knows which project will succeeded, the logical discussion of four possible ADR projects is applied in our work.

Laser Orbital Debris Removal (LODR, America) is shown in Figure 1(a). It is a 5-kilowatt laser that could possibly engage much space debris every day. Cube Sail (CS, the United Kingdom) is shown in Figure 1(b). It is the nano-satellite launched alone and guided to orbital debris under its own power. If the robot 'docks' with the debris, it opens its sail to pull the debris from space. Clean Space One (CSO, Switzerland)) is shown in Figure 1 (c) It is designed to grab hold of a piece of space debris and thrust it into the atmosphere, where it will be burned up. Space Debris Micro Remover (SDMR, Japan) is shown in Figure 1(d) [4]. It can remove debris on the base of the robot arm.

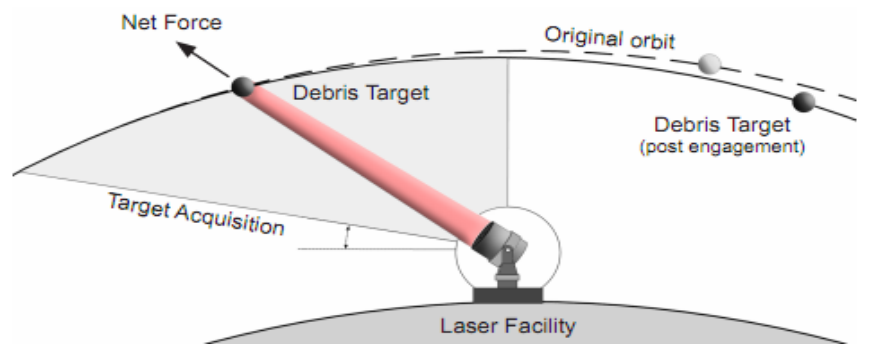

(a) LODR (Resource: http://www.space.com) 


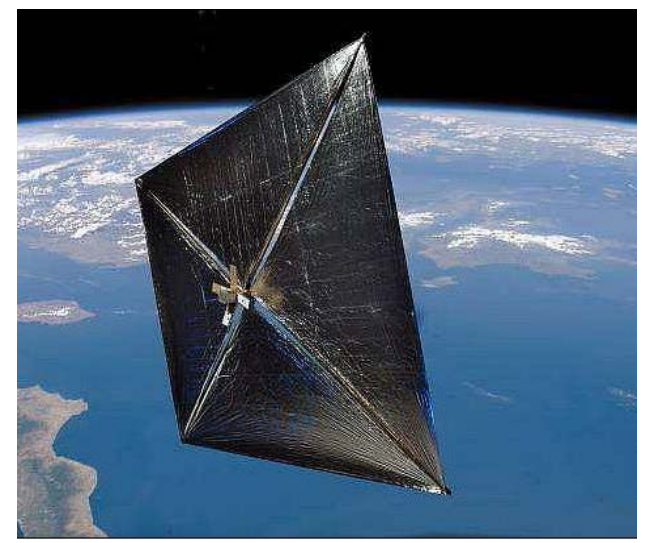

(b)CS (Resource: http://www.ipress.hr)

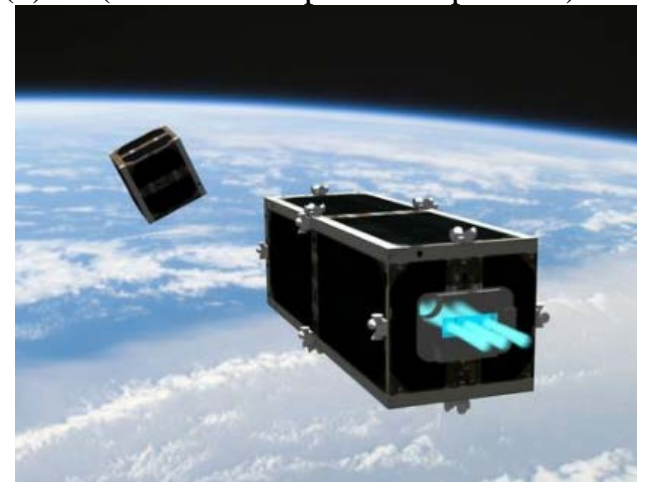

(c) CSO (Resource: http://www.cnbeta.com/articles/tech/172883.htm)

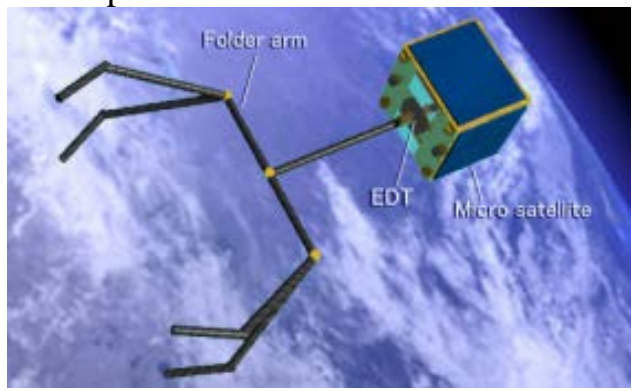

(d) SDMR

Figure 1. Schematic Diagram

\section{Profit-Evaluate Model}

Model Parameters. The model parameters are shown as Table 2.

Cost. For private firm, operating a space project is different from general commercial projects. In the early stage of research and construction, it is necessary to put a huge capital investment to the project. This part is generally supported by the state and the relevant foundation, or directly through loaning. Through many articles on the websites, we find the following facts of the four projects:

LODR. For LODR, we actually know that a piece of small debris costs 0.03 million dollars, a big debris costs 0.2 million dollars, and abandoned spacecraft cost 1 million dollars. And we reasonably simulate: research costs 20 million dollars, experiment costs 1 million dollars, product manufacturing costs 5 million dollars, maintaining costs 3 million dollars per year, salary costs 2 million dollars per year, operating costs 3 million dollars per year.

CS. For CS, we actually know that research costs 1.080 million dollars. And we reasonably simulate: experimental costs 0.5 million dollars, product manufacturing costs 0.001 million dollars, maintaining costs 0.2 million dollars per year, operating costs 0.1 million dollars, salary costs 0.3 million dollars per year. 
Table 2 .Model parameters

\begin{tabular}{cl}
\hline \multicolumn{1}{c}{ Symbol } & \multicolumn{1}{c}{ Meaning } \\
\hline$C(t)$ & The total cost of $t$ years \\
$C_{0}$ & Advance research and construction input \\
$C_{f}$ & The fixed cost per year \\
$\lambda$ & Annual growth rate of $C_{f}$ \\
$R(t)$ & The total revenue of $t$ years \\
$R_{f}$ & The fixed revenue per year \\
$\mu$ & Annual growth rate of $R_{f}$ \\
$\eta$ & Success rate \\
$\theta$ & If failed, insurance compensation of $C_{0}$ \\
$\varepsilon$ & Damage rate \\
$P(t)$ & Total profit expectation of $t$ years \\
$\rho(t)$ & The ratio of total profit expectation
\end{tabular}

CSO. For CSO, we actually know that research costs 10 million dollars, product manufacturing costs 8.64 million dollars. And we reasonably simulate: experimental costs 3 million dollars, maintaining costs 3 million dollars per year, operating costs 20 million dollars, salary costs 2 million dollars per year.

SDMR. For SDMR, we actually know that product manufacturing costs 4 million dollars. And we reasonably simulate: research costs 20 million dollars, experiment costs 20 million dollars, maintaining costs 3 million dollars per year, operating costs 20 million dollars, salary costs 2 million dollars per year.

The main parameters we have considered are advance research construction input, the fixed cost per year, annual growth rate of the fixed cost per year. As is shown in Table 3, the advance research and construction input includes research, experiment, product manufacturing; the fixed cost per year includes maintaining and salary per year; the growth rate of cost per year is estimated depending on those facts.

Table 3.The value of cost parameters

\begin{tabular}{cccc}
\hline Project & $\begin{array}{c}\text { Advance Research and } \\
\text { Construction Input } \\
C_{0}(\mathrm{M} \$)\end{array}$ & $\begin{array}{c}\text { Fixed Cost Per } \\
\text { Year }\end{array}$ & $\begin{array}{c}\text { Growth Rate of } \\
\text { Cost Per Year } \\
C_{f}\end{array}$ \\
\hline LODR & 20 & 6 & -0.5 \\
CS & 2 & 1 & 0.2 \\
CSO & 15 & 5 & -0.5 \\
SDMR & 30 & 5 & -0.5 \\
\hline
\end{tabular}

Overall, the cost function can be derived as follows.

$$
C(t)=C_{0}+\sum_{i=1}^{t} C_{f}(1+\lambda)^{i-1}
$$

Revenue. AS is shown in Figure 2, in recent years, the number of space debris increased significantly, which caused a great impact on human spacecraft. The space agency needs to put in a lot of manpower and material resources to monitor the debris and to avoid collisions. These are potential expense. Even in this case, the collision or the event has occurred, which is direct lost [5]. 


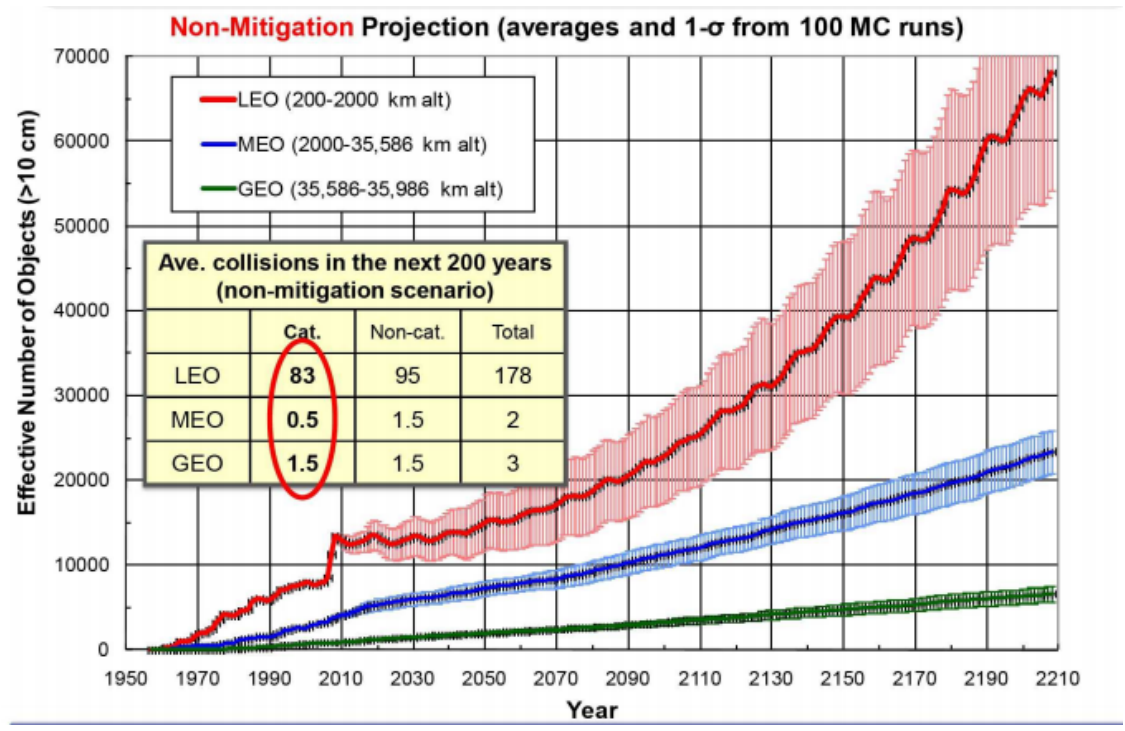

(a)The number of space debris

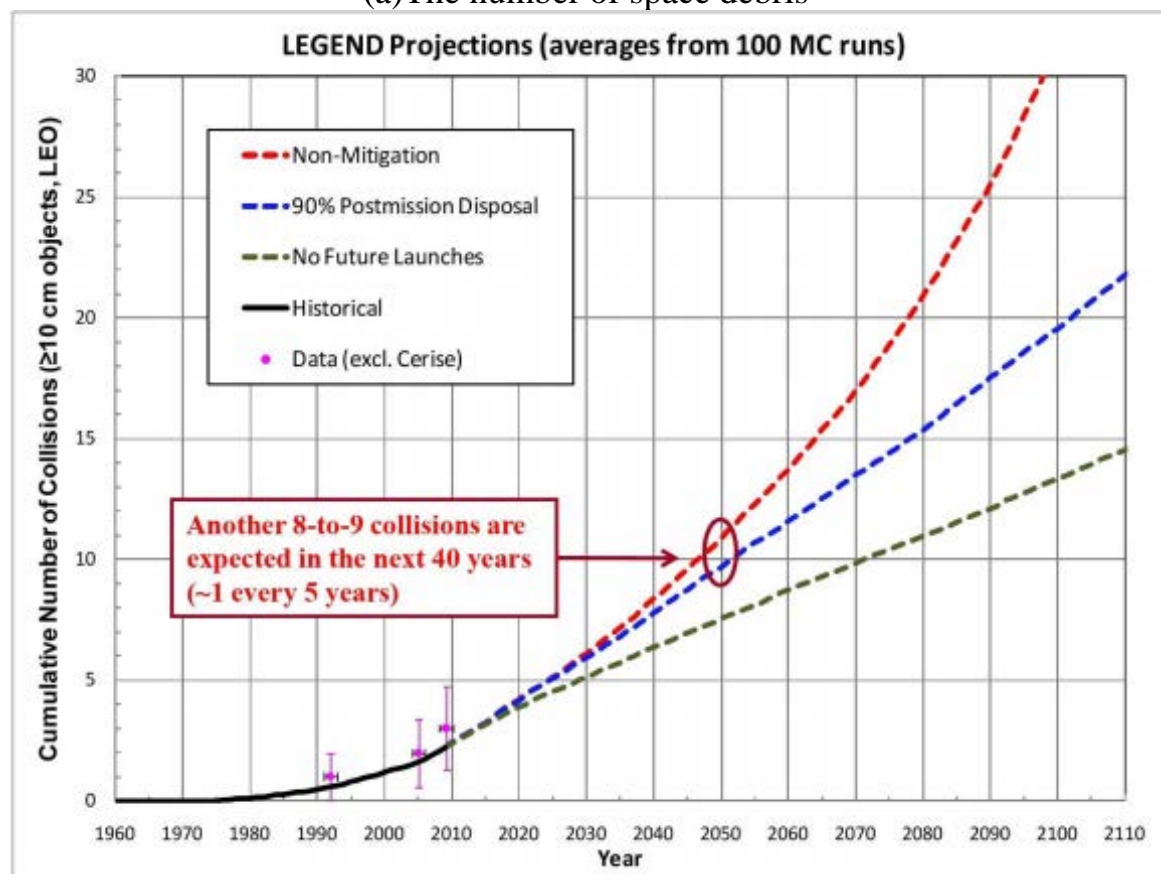

(b)Collision frequency

Figure2. The predictions of space debris

Obviously, ADR can reduce these costs for Space Agency. Therefore, we can believe that, there will be an organization (for example the United Nations Committee on the use of space for peaceful use of space) to give the private firms revenue. Also, according to the growth trend of NASA's prediction of the amount of debris, debris population will continue to increase. Therefore, the potential risk is bigger and bigger, and the removal of debris becomes increasingly important for countries. That is, the revenue will grow steadily.

The main parameters we have considered are the fixed cost per year $R_{f}$, annual growth rate of the fixed return per year $\mu$.Therefore, the main parameters of revenue can be simulated in Table 4:

Table 4. The value of revenue parameter

\begin{tabular}{|c|c|c|}
\hline Project & Fixed Revenue Per Year $R_{f}(\mathrm{M} \$)$ & Growth Rate of Revenue Per Year $\mu(\%)$ \\
\hline LODR & 9 & 3.0 \\
\hline CS & 5 & 5.0 \\
\hline CSO & 10 & 1.5 \\
\hline SDMR & 12 & 1.5 \\
\hline
\end{tabular}


Overall, the return function can be derived:

$$
R(t)=\sum_{i=0}^{t} R_{f}(1+\mu)^{i-1}
$$

Risk. The Laser Orbital Debris Removal technology is matured; the principle of Cube Sail is significantly simple than other projects. Also, LODR is operated on the ground, so the risk of damage is small; the simplicity of the cubic sail leads to a higher risk of damage. The main parameters of risk can be simulated in Table 5.

Table 5.The simulated value of risk parameters

\begin{tabular}{|c|c|c|}
\hline Project & Success Rate $\eta(\%)$ & Damage Rate $\varepsilon(\%)$ \\
\hline LODR & 9 & 0.1 \\
\hline CS & 5 & $\begin{array}{c}\text { 1(Small debris) } \\
\text { 5(Big debris) }\end{array}$ \\
\hline $\mathrm{CSO}$ & 10 & 3 \\
\hline SDMR & 12 & 3 \\
\hline
\end{tabular}

Profit. According the analysis for the cost, revenue and risk, we can know the total profit expectation for the first $t$ years.

If the project succeeds, there are also some products will be damaged. Therefore, for $t$ years, the project can earn

$$
(1-\varepsilon) \times R(t)
$$

Its profit is

$$
(1-\varepsilon) \times R(\mathrm{t})-\mathrm{C}(\mathrm{t})
$$

If the project breaks up, because part of the loss can be paid by the insurance, the loss will be

$$
(1-\theta) \cdot C_{0}
$$

Above all, we get the total profit

$$
P(\mathrm{t})=\eta[(1-\varepsilon) \cdot R(t)-C(t)]-(1-\eta)(1-\theta) \cdot C_{0}
$$

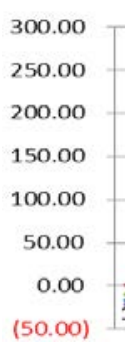

$(50.00)$
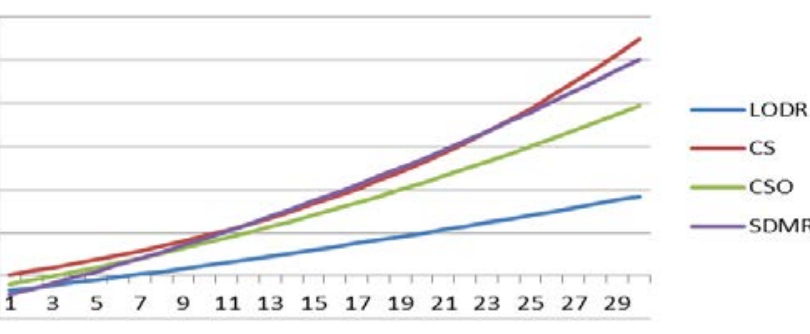

Figure 3. Total profit of first $t$ year

As is shown in Figure 3, firstly Cube Sail can get positive profit, and then profit of Space Debris Micro Remover exceeded cube Sail. But at the end, Cube Sail can obviously get more profit.

Then, we can easily know the rate of the profit:

$$
\rho(t)=\frac{P(t)}{C(t)}
$$

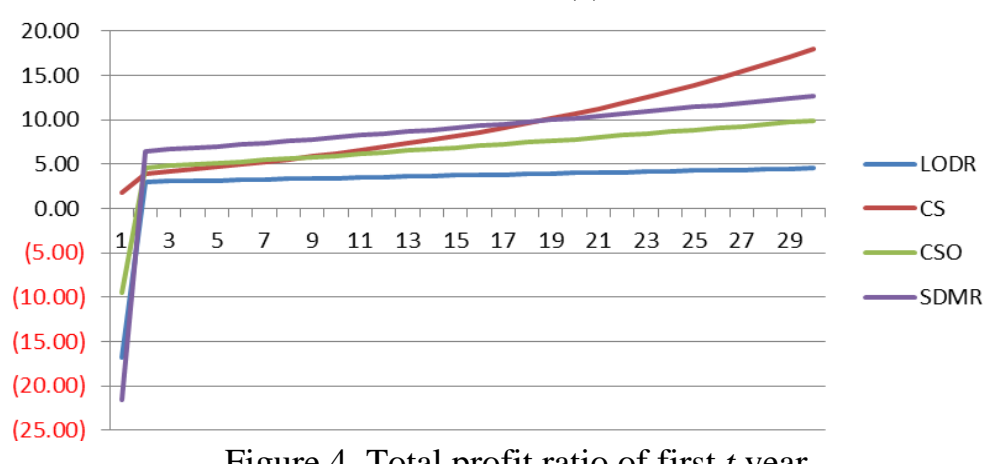

Figure 4. Total profit ratio of first $t$ year 
As is shown in Figure 4, the trend of the profit expectation is similar with its rate, and the rate of Cube Sail can finally be more than 15, which is much more than others.

Obviously, Cube Sail is the best project and Space Debris Micro Remover is the second. Since Cube Sail can get huge profits in the upper period, it is the most promising solution to address the space debris problem.

\section{Principal Components Analysis Model}

The evaluation of PCA is objective, and it can reduce information redundancy between evaluation indexes and evaluate investment projects [6] [7]. The evaluating indictor of four projects is shown in Table 6.

Table 6. Evaluating indictor of four projects

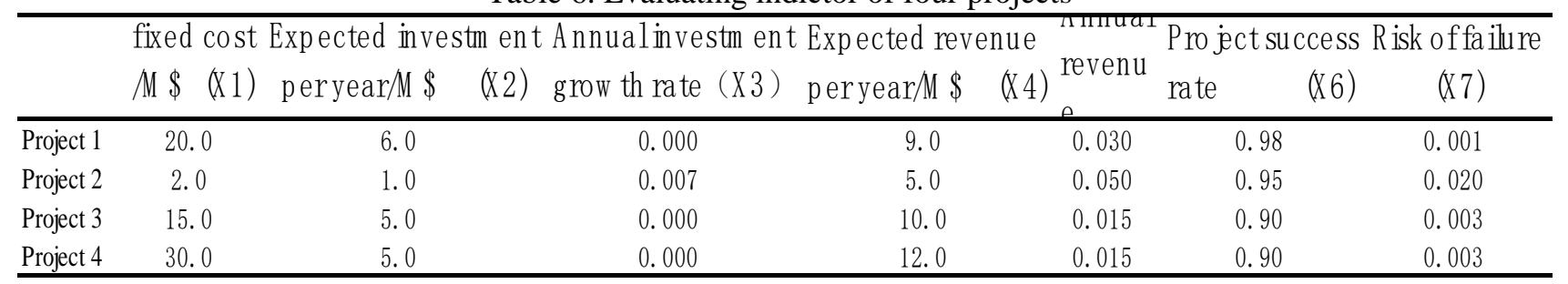

Note: Project1 Laser Orbital Debris Removal (LODB); Project2 Cube Sail (CS)

Project3 Clean Space One (CSO); Project4 Space Debris Micro Remover (SDMR)

Using the SPSS's analysis menu to do the principal component analysis, the principal component extraction analysis table and Scree Plot are shown in Table 7 and Figure5.

From the Table 7, the first two principal components contain $96.327 \%$ of the information of the total original data and their eigenvalue is bigger than 1 , therefore the first two principal components should be chosen to do a further analysis. The factor load matrix is shown as Table 8 , and the feature vector is shown as Table 9.

Table 7. The principal component extraction analysis table

\begin{tabular}{|c|c|c|c|c|c|c|}
\hline \multirow{2}{*}{$\begin{array}{l}\text { Principal } \\
\text { components }\end{array}$} & \multirow{2}{*}{\begin{tabular}{|l|} 
Principal \\
Eigenvalue
\end{tabular}} & \multicolumn{2}{|c|}{ component variance } & \multicolumn{3}{|c|}{ Appropriate item } \\
\hline & & \begin{tabular}{|c|} 
Contribution \\
rate \\
\end{tabular} & Sum & Eigenvalue & $\begin{array}{l}\text { Contribution } \\
\text { rate }\end{array}$ & Sum \\
\hline 1 & 5.604 & 80.061 & 80.061 & 5.604 & 80.061 & 80.061 \\
\hline 2 & 1.139 & 16.266 & 96.327 & 1.139 & 16.266 & 96.327 \\
\hline 3 & .257 & 3.673 & 100.000 & & & \\
\hline 4 & $3.092 \mathrm{E}-16$ & $4.418 \mathrm{E}-15$ & 100.000 & & & \\
\hline 5 & $5.455 \mathrm{E}-17$ & $7.793 \mathrm{E}-16$ & 100.000 & & & \\
\hline 6 & $-1.297 \mathrm{E}-16$ & $-1.852 \mathrm{E}-15$ & 100.000 & & & \\
\hline 7 & $-5.034 \mathrm{E}-16$ & $-7.192 \mathrm{E}-15$ & 100.000 & & & \\
\hline
\end{tabular}

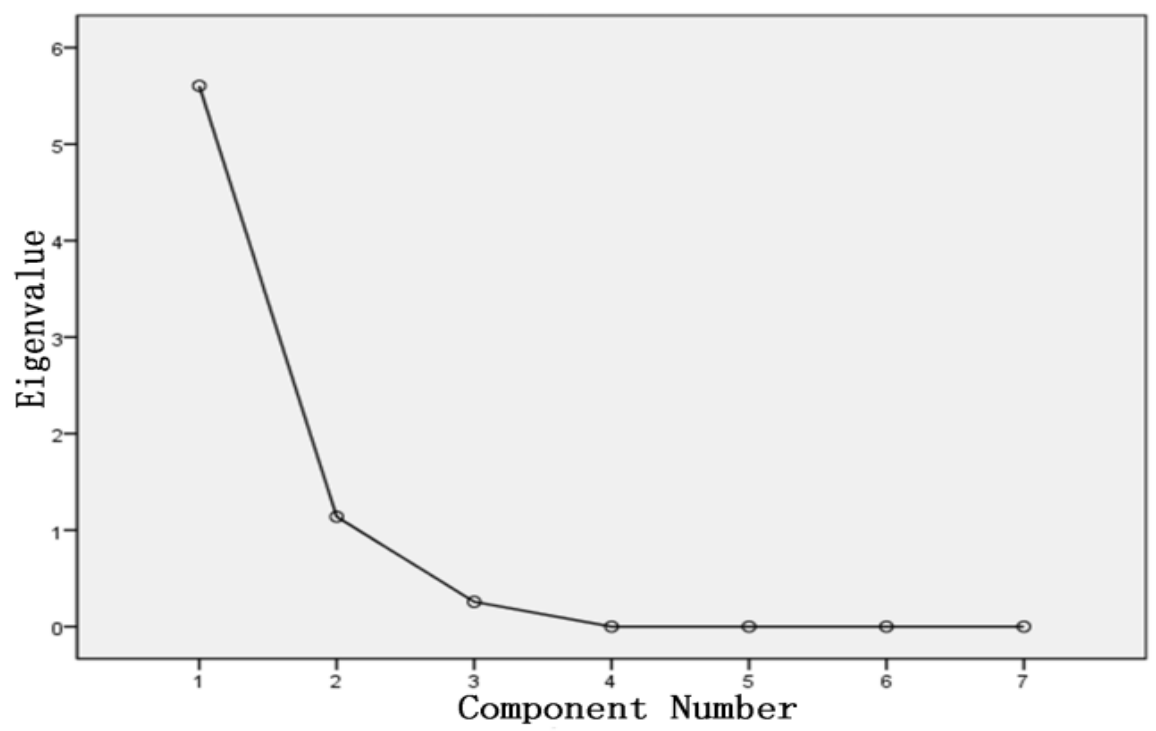

Figure 5. The scree plot 
Table 8. The factor load matrix

\begin{tabular}{|c|c|c|}
\hline \multirow{2}{*}{$\begin{array}{l}\text { Principal } \\
\text { component }\end{array}$} & \multicolumn{2}{|c|}{ Initial factor load matrix } \\
\hline & 1 & 2 \\
\hline $\mathrm{X} 1$ & -0.912 & 0.034 \\
\hline $\mathrm{X} 2$ & -0.918 & 0.379 \\
\hline X3 & 0.977 & -0.173 \\
\hline X4 & -0.976 & -0.165 \\
\hline X5 & 0.955 & 0.263 \\
\hline X6 & 0.450 & 0.889 \\
\hline$X 7$ & 0.953 & -0.277 \\
\hline \multicolumn{3}{|c|}{ Table 9. The feature vector } \\
\hline \multirow{2}{*}{$\begin{array}{l}\text { Principal } \\
\text { component }\end{array}$} & \multicolumn{2}{|c|}{ Feature vector } \\
\hline & 1 & 2 \\
\hline X1 & -0.163 & 0.030 \\
\hline $\mathrm{X} 2$ & -0.164 & 0.333 \\
\hline X3 & 0.174 & -0.152 \\
\hline $\mathrm{X} 4$ & -0.174 & -0.145 \\
\hline X5 & 0.170 & 0.231 \\
\hline X6 & 0.080 & 0.781 \\
\hline$X 7$ & 0.170 & -0.243 \\
\hline
\end{tabular}

From table 8, the first principal component $F_{1}$ mainly depends on $X_{5} X_{6} X_{7}$, which means the first principal component reflects annual investment, annual revenue growth rate and risk of failure. From table 9, the second principal component $F_{2}$ mainly depends on $X_{2}$, which means the second principal component reflects project success rate. $\mathrm{F}$ is used to combine $F_{1}$ and $F_{2}$, the variance contribution ratio is used as the weight coefficient:

$$
F=0.80061 F_{1}+0.16266 F_{2}
$$

Getting the result of $F$ by calculating, comprehensive ranking of the projects is showed in the table10.From Table 10, it is obvious that project 2 (Cube Sail) is the best project.

Table 10. The rank of four projects

\begin{tabular}{lrrrr}
\hline & $\begin{array}{c}\text { First principal } \\
\text { component }\end{array}$ & $\begin{array}{c}\text { Second principal } \\
\text { component }\end{array}$ & $\begin{array}{c}\text { Principal } \\
\text { component } \\
\text { score }\end{array}$ & Ranking \\
\hline Project 1 & -5.72 & 2.06 & -4.25 & 3 \\
Project 2 & -1.27 & 0.42 & -0.95 & 1 \\
Project 3 & -4.93 & 1.37 & -3.72 & 2 \\
Project 4 & -7.72 & 1.52 & -5.93 & 4 \\
\hline
\end{tabular}

\section{Conclusion}

Based the Profit Evaluate Model and Principal Components Analysis Model, the conclusion is that the best project is Cube Sail. The private firms can apply this project into business, and get a large amount of profit. 


\section{References}

[1] Kessler D J, Cour-Palais B.G. Collision frequency of artificial satellites: The creation of a debris belt [J]. Journal of Geophysical Research: Space Physics (1978-2012), 1978, 83(A6): 2637-2646.

[2] Liou J C, Johnson N L. Risks in space from orbiting debris[J]. Science, 2006, 311(5759): 340-341.

[3] Kaplan M H. Survey of space debris reduction projects [C]//Proceedings of AIAA SPACE 2009 conference \& exposition. 2009: 14-17.

[4] http://www.unoosa.org/pdf/natact/sdnps/2009/japan-sdE.pdf

[5] Liou J C. An assessment of the current LEO debris environment and the need for active debris removal [J]. 2010.

[6] Bin Mei Zhu, Zhang Hao, Zheng Huiting. Project cost risk analysis and sensitivity evaluation -Based on a friends of the BP model [J]. Accounting, 2012 (21): 8-10.

[7] Zhou Xuemei. Research on project investment decision based on principal component analysis [J]. Productivity Research, 2010 (10): 157-158. 